\title{
AC 2008-2065: A SPIRAL CURRICULUM APPROACH TO THE IMPLEMENTATION OF INSTRUMENTATION IN BIOLOGICAL SYSTEMS ENGINEERING
}

\section{Kumar Mallikarjunan, Virginia Polytechnic Institute and State University}

Dr. Kumar Mallikarjunan is an associate professor in Biological Systems Engineering at Virginia Tech. He is interested in understanding and implementing a spiral theme based engineering curriculum for the Biological Systems Engineering program, engineering ethics, and promotion of undergraduate research.

\section{Anand Lakshmikanth, Virginia Polytechnic Institute and State University}

Mr. Anand Lakshmikanth, doctoral student in Biological Systems Engineering at Virginia Tech, has been actively engaged in learning about curriculum development in addition to pursuing his research related to computational modeling of high pressure processing.

\section{John Cundiff, Virginia Polytechnic Institute and State University}

Dr. John Cundiff is a professor in Biological Systems Engineering at Virginia Tech. He is interested implementing a spiral theme based engineering curriculum for the Biological Systems Engineering program, specifically in the sophomore year.

\section{Andrew Fulton, Virginia Polytechnic Institute and State University}

Mr. Andrew Fulton, an undergraduate student in the Biological Systems Engineering program at Virginia Tech, has participated in a NSF REU program and helped develop the activities related to this article. 


\title{
A Spiral Curriculum Approach to the implementation of Instrumentation in Biological Systems Engineering
}

\begin{abstract}
The Engineering Education and Biological Systems Engineering departments at Virginia Tech have identified a need for a spiral themed curriculum in undergraduate engineering education. Approval for carrying out studies in implementing the spiral curriculum was approved in the Biological Systems Engineering (BSE) department in November 2007 by the university's Internal Review Board allowing the investigators to conduct their studies by gaining access to and analyzing student responses, course materials, and student participation for the efficacy of the implementation of the spiral curriculum.

The first phase of an assignment module was implemented in a sophomore level course during the Fall semester of 2007. The module involved introducing data acquisition and control concepts to students through lecture sessions, assignments, and hands-on experience with setting up a circuit, a data acquisition unit, and utilization of the LabVIEW software in acquiring data. Student understanding of the concepts was evaluated by subjecting the students to five pre- and post-test survey questions, four of which were set up on a 5-point Likert scale. Results of a paired t-test analysis performed on Likert scale responses of 14 students indicated a significant change between pre-and post-test for two of the four questions answered. Student responses in the post-test quiz and survey indicated a similarity in terms of knowledge gained through the module, and indicated a better understanding of terms like precision, accuracy, and concepts of controlling a system. The first phase of implementation will be followed by a second phase involving control of a system during the Spring semester of 2007.
\end{abstract}

\section{Background}

The twentieth century psychologist, Jerome Bruner, proposed the concept of the spiral curriculum. Bruner advocates that a curriculum as it develops should revisit the basic ideas repeatedly, building upon them until the student has grasped the full formal apparatus that goes with them ${ }^{3}$. According to Harden and Stamper ${ }^{11}$, a spiral themed curriculum achieves its purpose by means of deepening of a topic through subsequent re-visitations, rather than merely its repetition.

Evidences of implementation of a spiral curriculum approach in engineering and other fields of study have been reported. Curriculum design ${ }^{5}$, implementation ${ }^{8}$, and evaluation ${ }^{7}$ of the spiral curriculum on the first-year chemical engineering curriculum have been reported by department of Chemical Engineering in Worcester Polytechnic Institute, Worcester, MA. The efficacy of a mathematical programming language Zeno, which facilitates Bruner's concepts of spiral-based curriculum, has also been reported by the Graduate School of Education in The Queen's University of Belfast, Northern Ireland ${ }^{6}$.

An NSF sponsored collaboration between the departments of Engineering Education (EngE) and the bioprocess wing of the Biological Systems Engineering (BSE) at Virginia Tech was launched in September 2004. The first project was awarded in Fall of 2003 and became a planning project 
for the second funding from NSF for the DLR. This DLR project, funded in Fall 2004, focused on reformulating the engineering curriculum for specifically bioprocess engineering program in the Department of Biological Systems Engineering in conjunction with the freshman program in the Department of Engineering Education and School of Education ${ }^{12}$. The formed committee assessed a need for students improving their skills by having them continuously revisit key concepts, which increased in levels of complexity, through a four-year spiral themed curriculum. The focus of the curriculum was on active learning of concepts of design, systems, and ethics through hands-on activities or learning modules as is indicated in figure 1.

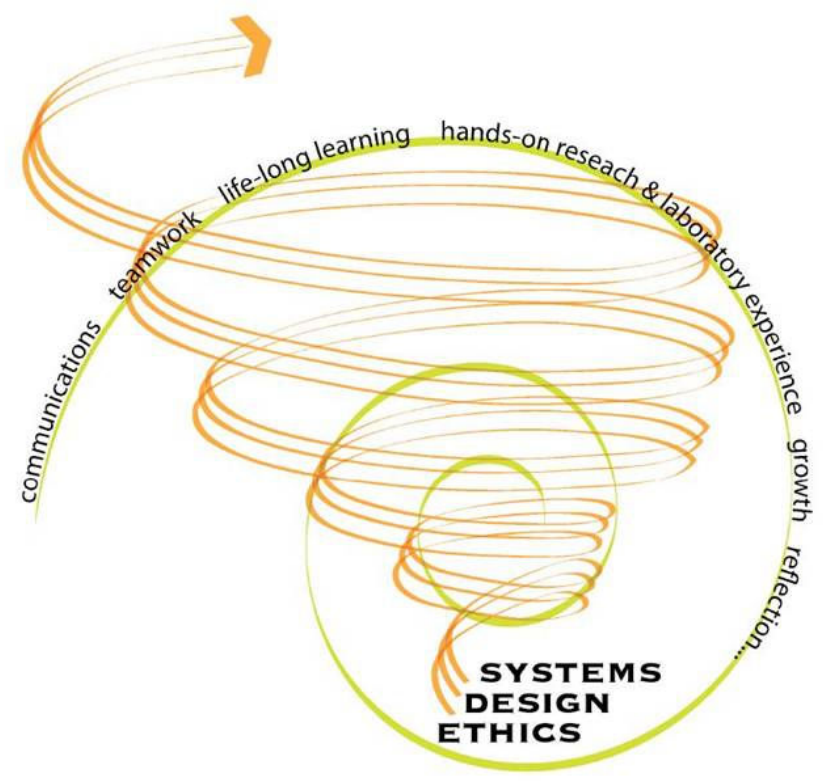

Figure 1. Schematic representation of the spiral curriculum indicating re-visitation and deepening of concepts pertaining to systems approach, engineering design, and ethics

Some of the activities planned under the DLR project included use of electronic portfolios in engineering instruction, development of student team building software, incorporating research and cutting edge laboratory experiences into the undergraduate curriculum ${ }^{14}$. Studies in implementation and evaluation of the spiral-based curriculum from Virginia Tech have recently been reported on ethics ${ }^{16,17}$ and systems concept ${ }^{13}$. Currently, the DLR project is undertaking many studies on implementation and evaluation of the spiral-based curriculum in freshman engineering and undergraduate program in the BSE department, and the following is a report on implementation and evaluation of introducing instrumentation at the sophomore level in the BSE department.

Incorporating systems thinking

It is essential to incorporate systems thinking in influencing learning outcomes in engineering design. In a real world scenario, in order to cope with complexities in design, it is essential that students in engineering incorporate holistic thinking in terms of understanding system concepts and interactions between components in order to control it. Such holistic thinking involves 9 
- Thinking about system dynamics

- Reasoning about uncertainty,

- Making estimations

- Conducting experiments

Systems-based learning has been actively incorporated by the DLR research group in various modules assigned to freshman engineering students. The combination of six levels of Bloom's taxonomy with systems-based learning aiding students to recognize, interpret, implement, organize, evaluate, and create solutions for engineering design ${ }^{10}$ is of vital importance to graduating engineers. Through the hands-on activity in our proposed module, students will learn to control the attributes of a system by acquiring data from its components and their interactions

\section{Data Acquisition and Control in Biological Systems Engineering}

Integration of computer-based data acquisition (DAQ) and controls into the current curriculum for BSE is an effort consistent with the DLR involving a spiral curriculum that BSE is attempting to adopt. Knowledge of acquisition and control systems and their application to real world situations will be constantly disseminated throughout the undergraduate program. This knowledge, combined with hands-on laboratory experience was deemed essential to produce a well-rounded BSE graduate, since a large portion of understanding biological systems is through accurate and precise data acquisition.

The proposed plan was to introduce the basic concepts of acquisition and control systems in two phases, through two courses taught by the BSE department at the sophomore level. The course "Introduction to Biological Systems Engineering", taught during Fall and Spring semesters under course numbers BSE 2105 and BSE 2106 was chosen for implementation of the module. These will be discussed in the methodology section of this report.

\section{$\underline{\text { Rationale and Objectives }}$}

A major limitation for students in the BSE program is that their current exposure to instrumentation is only through a senior-level course. The students have no prior introduction to basic concepts of instrumentation, prior to this afore mentioned course in instrumentation. Students in their senior year in the bioprocess engineering option of BSE have to undertake courses like plant design, bioprocess engineering, protein engineering and food process engineering in addition to the senior design project. The timing is therefore not appropriate and thus there is a need for exposure to concepts of instrumentation at an early stage in the undergraduate program. According to the proposed DLR, an effective knowledge-based learning requires the knowledge to be introduced at the sophomore level, and revisited throughout the program, until the undergraduate thoroughly understands how to apply the knowledge of computer-based data acquisition to real-life problems. 
The specific objectives were that after a successful completion of the modules, the individual student should be able to

- define and differentiate between sensor and control

- define and differentiate between precision and accuracy

- measure physiological properties such as temperature and $\mathrm{pH}$

- control a system based on component interactions

- describe the spectrum of control from manual to automatic

\section{Methodology}

This report discusses the implementation and evaluation of the first phase of implementation of instrumentation of instrumentation for sophomore BSE students. This first phase involved students to understand basic concepts of acquisition and control, and utilize the concepts of acquisition in procuring data from a given system through a DAQ unit and a computer interface. The software used for data acquisition was LabVIEW, short for Laboratory Virtual Instrumentation Workbench. Developed by National Instruments ${ }^{1}$, LabVIEW utilizes a dataflow programming language which allows the user to regulate the execution sequences by connecting different functions or operators through wires. Such a constructed architecture is known as a "virtual instrument," which utilizes an interface or front panel to communicate with the user. LabVIEW is a powerful tool that facilitates data acquisition and control, real-time analysis and computing, graphical programming, automated testing, and design and prototyping systems using a unique embedded design ${ }^{1}$. LabVIEW applications have been in deep-sea exploration, crude-oil distribution, medicine, distance learning ${ }^{15}$, and most notably in the functioning of the large Hadron collider at CERN in Switzerland ${ }^{4}$.

The first phase, held over a two-week period, was implemented as follows

- Pre-test survey

- Lecture sessions on sensors and controls

- Lecture session on LabVIEW, including in-class LabVIEW activity

- Pre-test LabVIEW homework

- Lecture session on data acquisition basics

- Hands-on data acquisition using DAQ interface and LabVIEW

- Post-test quiz

- Post-test survey

Students were instructed to download and install the LabVIEW trial software and the DAQ-MX assistant drivers prior to the first lecture session.

\section{Pre-Test Survey}

An optional pre-test survey, conducted during the first of two lecture sessions, included 5 questions that the students answered. The pre-test survey was completed by the students on November $8^{\text {th }} 2007$ during their laboratory session for BSE 2105. Prior to the survey, the students were asked to read and approve an informed consent form to evaluate their responses for the DLR study. The form listed in detail the purpose, procedures, risks, and extent of 
anonymity of the proposed implementation of the spiral theme-based curriculum. Students were given freedom to withdraw at anytime without penalty. Students were also asked to give their voluntary consent to the investigators to:

- Utilize coursework, including homework assignments, quizzes, and test-scores

- Contact the concerned student about anonymous participation in video/audio-recorded focus group sessions and/or oral presentations at the end of the semester

- Obtain the concerned student's GPA and SAT data from the institutional research office

Four out of the five questions posed in the survey were designed on a 5-point Likert scale (Strongly Agree, Agree, Neutral, Disagree, and Strongly Disagree). The fifth question required a hand-written response and the questions posed to the students were designed based on a possible change in response after the activity was completed. The questions posed to the students were as follows,

Q1. I can define and differentiate between sensor and control

Q2. I can define precision and accuracy and explain the difference between the two

Q3. I understand the importance of controlling a biological system is for getting maximum benefit from the system

Q4. I can define the term sensitivity and know its importance with measurement and control

Q5. Name at least three important properties of biological systems that can be measured

\section{$\underline{\text { Lecture Sessions }}$}

Two lecture sessions were utilized to introduce instrumentation through basic concepts of sensors and controls, precision, accuracy, and sensitivity, data acquisition, and basic LabVIEW training, including an in-class math-based activity on LabVIEW. The in-class activity was similar to the one assigned for freshman engineering students, since the sophomore students had no prior exposure to the software.

\section{Pre-test LabVIEW Homework}

Two LabVIEW problems were assigned to students in order for them to familiarize themselves to the software before the hands-on data acquisition activity. In addition, the homework included a written summary on LabVIEW tutorials and applications, that the students were instructed to view. The homework was collected a week later and used for analysis.

\section{Data acquisition using DAQ interface and LabVIEW}

A bus-powered, NI-USB6008 DAQ unit (National Instruments Corporation, Austin, TX), with eight 12-bit, analog inputs and two outputs was used for acquiring temperature from a NTC-102$\mathrm{R}$ thermistor (manufactured by Jameco Electronics, Belmont, CA). The simple set-up is depicted in the circuit diagram given in figure 2 , which was assembled on a breadboard. 


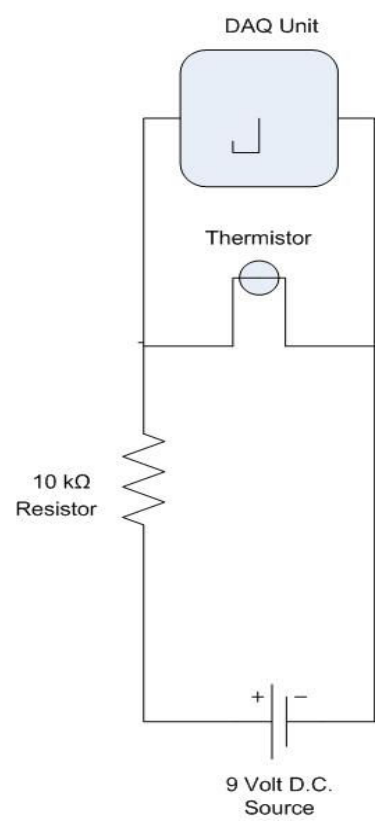

Figure 2. Circuit diagram for temperature data acquisition using a thermistor and a DAQ unit

Thermistor resistance-temperature (R-T) modeling is best described by the Steinhart-Hart equation, which is a representation of the R-T relationship, derived through curve-fitting techniques and evaluation of the R-T characteristic of thermistor devices ${ }^{2}$. The equation is given by

$$
\frac{1}{T}=a+b * \ln (R)+c * \ln ^{3}(R)
$$

where a, b, and c are device-specific Steinhart-Hart parameters, $\mathrm{R}$ is the resistance in ohms, and $\mathrm{T}$ is the temperature in Kelvin. The values of $\mathrm{a}, \mathrm{b}$, and $\mathrm{c}$ for the thermistor utilized in the temperature acquisition activity were $1.10928 \times 10^{-03}, 2.439 \times 10^{-04}$, and $1.018703 \times 10^{-07}$, respectively. These values were entered in the LabVIEW interface for the DAQ unit, which enabled it to acquire the signal from the thermistor and feed it to the LabVIEW user-interface. A sample VI for the temperature acquisition system is given in figure 3.

Students were asked to verify the response of the acquisition by artificially increasing and the temperature around the thermistor by grasping it tightly or blowing cold air over it, and then allowing the thermistor to return to room temperature. 


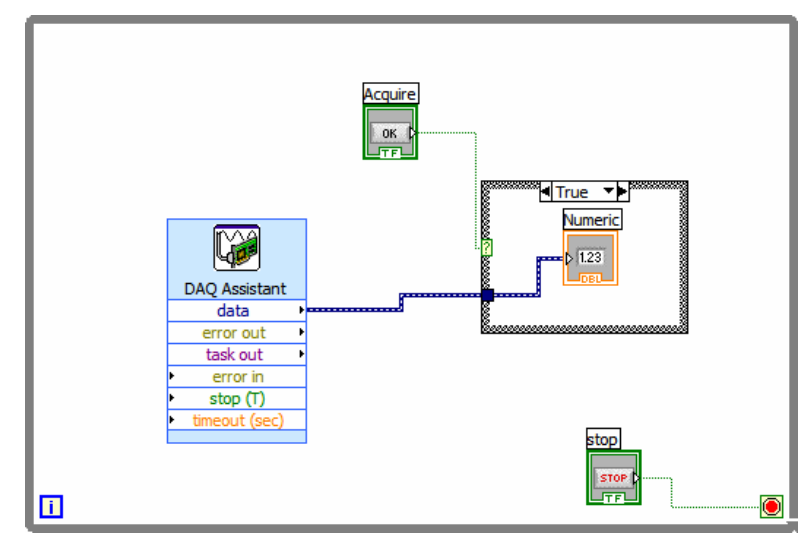

Figure 3. LabVIEW virtual instrument for temperature data acquisition

\section{Post-test quiz and survey}

The post-test quiz and survey were completed by the students on $29^{\text {th }}$ November, 2007, with the quiz preceding the survey. The quiz included five questions pertaining to the content covered during the two lecture sessions, but did not include any LabVIEW-based questions. Questions posed in the quiz required one-line or one-paragraph responses, with one multiple-choice question. The following questions were in the quiz,

Q1. Classify the following data in terms of precision and accuracy: $8 \mathrm{~g} / \mathrm{mol}, 7 \mathrm{~g} / \mathrm{mol}, 14$ $\mathrm{g} / \mathrm{mol}, 10 \mathrm{~g} / \mathrm{mol}, 21 \mathrm{~g} / \mathrm{mol}$. The acceptable value is $4 \mathrm{~g} / \mathrm{mol}$

Q2. Define the term sensitivity

Q3. A control system achieves its desired results through:

\section{Positive feedback}

Negative feedback

Precise data acquisition

All of the above

None of the above

Q4. What is one major difference between an analog and a digitized signal?

Q5. What are the two variables related to using the Steinhart-Hart equation?

The post-test survey was conducted after the quiz, and the same five pre-test questions were posed to the students as post-test questions.

\section{Results}

\section{Assessment of homework}

The homework assigned to sophomore BSE students involved developing VI for two problems; one involving Boolean logic and the other involving a nested/IF-ELSE structure that also included artificial signal simulation. In addition to the VI development, students were asked to view two videos on the National Instruments website. One video was titled "Acquire, Analyze, 
and Present with National Instruments LabVIEW" and the other "Cool LabVIEW Applications." Students were asked to write a summary on the viewed videos.

Though the LabVIEW portion of the homework assignment did not relate much to the VI development in the data acquisition activity, the aim was to provide a simple assignment for students to familiarize and learn more about LabVIEW.

Students were very enamored by the "Cool LabVIEW applications" video and found the video very informative and instrumental in learning more about the software. Some of these comments were found in the summary.

“...it's amazing and incredible the things LabVIEW can be applied to."

"I actually enjoyed this video. It showed why it is important that we learn to use this software. I feel motivated to learn something if there is a reason why I am learning it."

"This video showed LabVIEW used at its potential. The soccer robot was the most interesting part. This video was much better than the previous one for showing what can be done with LabVIEW by using real life examples."

The assigned homework was not graded, but all students had done the assignment to reasonably satisfactory levels.

\section{Data Analysis and Assessment of Pre- and Post-Test Surveys}

Since participation in the surveys was considered optional as per rules of the Internal Review Board (IRB) at Virginia Tech, 15 out of 16 students in the class signed their consent forms, and participated in the pre-test survey on $8^{\text {th }}$ November, 2007. However on $29^{\text {th }}$ November, 2007 , only 14 of the 15 participating students showed up in class to take the post-test survey. In order to analyze each individual's responses for pre- and post-tests separately for assessment, a final of 14 responses were evaluated. Statistical data analysis was performed on the 5-point Likert scale responses of the students' response to the five questions posed in the pre- and post-test surveys for questions 1 to 4 . Response of students to question 5 was analyzed separately. For the purposes of analysis, the Likert scale responses were numbered 1 to 5, from Strongly Agree to Strongly Disagree. Table I gives the modal value of responses in the pre-and post-workshop responses to the questions in the order listed in the methodology section.

The data was then subjected to repeated measures analysis using correlated t-test to find any significant differences in the means between the pre-and post-workshop responses. Statistical analysis was conducted on SAS software (version 9.1). Table 2 indicates the Pearson's correlation and P-values for the two-tailed t-test. 
Table 1: Statistical summary of Likert scale responses in pre- and post-test surveys (Q1-Q4)

\begin{tabular}{|l|c|c|c|c|}
\hline \multicolumn{1}{|c|}{ Question } & $\begin{array}{c}\text { Modal Pre- } \\
\text { Test Response }\end{array}$ & $\begin{array}{c}\text { Standard } \\
\text { Deviation }\end{array}$ & $\begin{array}{c}\text { Modal Post- } \\
\text { Test Response }\end{array}$ & $\begin{array}{c}\text { Standard } \\
\text { Deviation }\end{array}$ \\
\hline $\begin{array}{l}\text { I can define and differentiate } \\
\text { between sensor and control }\end{array}$ & 3 (Neutral) & 0.99 & 2 (Agree) & 0.95 \\
\hline $\begin{array}{l}\text { I can define precision and accuracy } \\
\text { and explain the difference between } \\
\text { the two }\end{array}$ & 2 (Agree) & 0.63 & $\begin{array}{c}1 \text { (Strongly } \\
\text { Agree) }\end{array}$ & 0.67 \\
\hline $\begin{array}{l}\text { I understand the importance of } \\
\text { controlling a biological system is } \\
\text { for getting maximum benefit from } \\
\text { the system }\end{array}$ & 2 (Agree) & 0.70 & 2 (Agree) & 0.48 \\
\hline $\begin{array}{l}\text { I can define the term sensitivity and } \\
\text { know its importance with } \\
\text { measurement and control }\end{array}$ & 3 (Neutral) & 0.67 & 2 (Agree) & 0.52 \\
\hline
\end{tabular}

Table 2. Pearson's Correlation and P-Values for t-test analysis on pre- and post-test Likert scale responses

\begin{tabular}{|l|c|c|}
\hline \multicolumn{1}{|c|}{ Question } & $\begin{array}{c}\text { Pearson's Correlation } \\
\text { Coefficient (Pre vs Post) }\end{array}$ & P-Value \\
\hline $\begin{array}{l}\text { I can define and differentiate between sensor } \\
\text { and control }\end{array}$ & 0.50 & 0.03 \\
\hline $\begin{array}{l}\text { I can define precision and accuracy and explain } \\
\text { the difference between the two }\end{array}$ & -0.11 & 0.17 \\
\hline $\begin{array}{l}\text { I understand the importance of controlling a } \\
\text { biological system is for getting maximum } \\
\text { benefit from the system }\end{array}$ & 0.10 & 0.007 \\
\hline $\begin{array}{l}\text { I can define the term sensitivity and know its } \\
\text { importance with measurement and control }\end{array}$ & 0.33 & 0.14 \\
\hline
\end{tabular}

\section{$\underline{\text { Assessment of statistical data with student responses }}$}

A positive response was defined as the one in which students answered "Agree" or "Strongly Agree" in the post-test after answering "Neutral", "Disagree" or "Strongly Disagree" response in the pre-test. The reverse case was considered a negative response. A response change from "Disagree" or Strongly Disagree" to "Neutral" was not considered an improvement in response for our assessment.

From table 2, it can be indicated that the student responses between the pre- and post-test, for questions 1 and 3 varied significantly due to the implementation of the module. A detailed analysis of responses to these questions indicated that for questions 1 and 3,50\% of the students responded positively to the module. While question 2 also yielded a similar result, almost all of the improvement was from "Agree" in the pre-test to "Strongly Agree" in the post test and most 
likely affected the significance of improvement. For question 4, only $21 \%$ of the students showed any a positive response, while $60 \%$ of the responses indicated no change between the pre- and post-test. There was only one negative response each by three separate students for questions 1 , 2 , and 4 .

Since the response to question 5 could not be analyzed statistically, a qualitative assessment was made based on the type of responses. Table 3 indicates some sample responses for pre- and posttest for question 5 .

Table 3. Pre- and post-test responses for question 5

\begin{tabular}{|l|l|l|}
\hline \multicolumn{1}{|c|}{ Question } & \multicolumn{1}{|c|}{ Sample Pre-test Responses } & \multicolumn{1}{|c|}{ Sample Post-test Responses } \\
\hline Name at least three important & Temperature, Moisture & Temperature, Moisture \\
properties of biological & Content, Population, Area, & Content, Population, pH, \\
systems that can be measured & Rainfall, Soil content, & Mass, Density, Frequency, \\
& Pollution, Water Quality, & Concentration, Run-off, \\
& Health, Precision & Surface Area \\
\hline
\end{tabular}

It was found that the responses for this question in the post-test were more refined, with measurable quantities such as temperature and moisture content appearing more often than in the pre-test. Three students who did not respond to this question in the pre-test responded with reasonable clarity in the post-test. In addition, there were fewer occurrences of vague and unclear responses such as "precision", "hydrology", "sustainability", "accuracy" etc. in the post-test when compared to the pre-test.

\section{$\underline{\text { Assessment of post-test quiz }}$}

As mentioned earlier, the post-test quiz was offered in the same session prior to the post-test quiz. Only 14 out of 16 responses were evaluated because of a student unable to be present during the session and one student's refusal to allow their homework or quiz be used for analysis in the consent form. Results of the responses to questions 1 through 5 in the posed quiz, in terms of percentage of students answering the question right or wrong is listed in table 4. Assessment of the question requiring a short answer as right or wrong (questions 1,2, and 4) was based on the clarity of the response.

Table 4. Right and wrong responses from the post-test quiz

\begin{tabular}{|c|c|c|}
\hline Question & Right Responses & Wrong Responses \\
\hline Classify data in terms of precision and accuracy & 10 & 4 \\
\hline Define the term sensitivity & 7 & 4 \\
\hline $\begin{array}{c}\text { A control system achieves its desired results } \\
\text { through.. }\end{array}$ & 10 & 11 \\
\hline $\begin{array}{c}\text { What is one major difference between an analog } \\
\text { and a digitized signal? }\end{array}$ & 3 & 12 \\
\hline $\begin{array}{c}\text { What are the two variables related to using the } \\
\text { Steinhart-Hart equation? }\end{array}$ & 2 & \\
\hline
\end{tabular}


Evaluation of the student responses from the table indicates that majority of the students had a better understanding of the terms precision and accuracy and basic underlying concepts of controlling a system after the module implementation. However, only half of the students answered correctly to the definition of sensitivity and performed poorly on the remaining two responses.

From the survey question analysis it was ascertained that questions 1 and 3 indicated significant changes from pre- to post-test, and questions 1,2, and 3 showed $50 \%$ of the students responding positively to the module. Upon comparison of the quiz results to the pre- and post-test survey data analysis, it was found that their performance on the first three questions of the quiz conformed to their responses in the surveys. Questions pertaining to precision and accuracy and controlling a system, that were answered correctly by 10 out of 14 students in the quiz showed positive response in the survey analysis. While the quiz reflected that only 7 out of 14 students answered the question on sensitivity correctly, it was corroborated by the survey response where only 3 students responded positively, and student responses on understanding the concept of sensitivity were predominantly "Neutral."

\section{$\underline{\text { Discussion and future research }}$}

While the first phase of module was implemented with a moderate amount of success, attested by positive student responses to some questions on the quiz and the survey, the investigators felt that the two-week duration of implementation allowed very limited exposure to the concepts of instrumentation in terms of data acquisition and control. In addition, the implementation of the first phase was towards the end of the Fall semester, during which time students were focused more on their curriculum courses. A better assessment is only possible when the second phase, which will involve hands-on activity in controlling a system using knowledge data acquisition techniques and LabVIEW, is implemented in Spring 2008 in BSE 2106. The lecture schedules for this phase will go more in detail on instrumentation concepts and LabVIEW software, while revisiting and deepening concepts covered in the first phase. An assessment of student responses after this second phase will be a better indicator of a successful implementation of the spiral themed curriculum. More approaches like these, combined with preexisting teaching modules are required to improve the ability of undergraduates in engineering to understand concepts and become more aware towards a multi-disciplinary approach.

\section{Acknowledgements}

The authors of this paper would like to acknowledge the financial support of the National Science Foundation (grant number 0431779). 


\section{Bibliography}

1. Anonymous. "What is NI LabVIEW?," available at http://www.ni.com/labview/whatis. Accessed on 5 January 2008.

2. Anonymous. "Thermistor calibration and the Steinhart-Hart equation," available at http://www.ilxlightwave.com/appnotes/thermistor_calibration_steinhart-hart_equation.pdf. Accessed on 5 January 2008.

3. Bruner, J., The Process of Education. Cambridge, 1960 MA: Harvard University Press.

4. Butterworth A., J. Molendijk, R. Sorokoletov, and F.Weierud, "Control of the low level RF system of the large Hadron collider" in $10^{\text {th }}$ Int. Conf. on Accelerator \& Large Expt. Physics Control Systems, Geneva, Switzerland, October 10-14, 2005.

5. Clark, W.M., D. DiBiasio, and A.G. Dixon, "A project-based, spiral curriculum for introductory courses in chemical engineering: I. Curriculum Design" in Chem. Eng. Ed., 34(3), 222-228, 2000.

6. Cowan, P., H. Morrison, and F. McBride, "Evidence of a spiral curriculum using a mathematical problemsolving tool" in Interactive Learning Environments, 6 (3), 205-224, 1998.

7. DiBiasio, D., L. Comparini, W. M. Clark, and A. G. Dixon, "A project-based, spiral curriculum for chemical engineering: III. Evaluation" in Chem. Eng. Ed., 35(2), 140-146, 2001.

8. Dixon, A.G., W.M. Clark, and D. DiBiasio, "A project-based, spiral curriculum for introductory courses in chemical engineering: II. Implementation" in Chem. Eng. Ed., 34(4), 296-303, 2000.

9. Dym, C.L., A.M. Agoino, O. Eris, D.D. Frey, and L.J. Leifer, "Engineering design, thinking, teaching, and learning" in Journal of Engg. Edu., 94 (1), 103-120, 1995.

10. Froyd, J., L. Pchenitchnaia, D. Fowler, and N. Simpson, "Systems thinking and integrative learning outcomes" in Proceedings of the 2006 ASEE Annual Conference and Exposition, Honolulu, HI, June 24-27, 2007.

11. Harden, R.M. and N. Stamper, "What is a spiral curriculum?" in Medical Teacher, 21(2), 1999.

12.Lohani, V.K., P. Mallikarjunan, M.L. Wolfe, T. Wildman, J. Connor, J. Muffo, J. Lo, T.W. Knott, G.V. Loganathan, R. Goff, M. Chang, J. Cundiff, G. Adel, F. Agblevor, M. Gregg, D. Vaughan, E. Fox, H. Griffin, and S.Mostaghimi, "Work in progress- Spiral curriculum approach to reformulate engineering curriculum" in Proceedings of the ASEE/IEEE Frontiers in Education Conference, Indianapolis, IN, October 19-22, 2005.

13. Mallikarjunan, P., A. Lakshmikanth, M.L. Wolfe, V.K. Lohani, and J.B. Connor, "Introduction to systems approach using bio-energy resources as a tool for freshman engineering education" in Proceedings of the 2007 International Conference on Engineering Education, Coimbra, Portugal, September 3-7, 2007.

14. Muffo, J., V.K. Lohani, J. Mullin, R. Backert, and H. Griffin, "From Engineering Fundamentals to Engineering Education- What's in a name?" in Proceedings of the International Conference on Engineering Education \& Research (iCEER05), Tainan, Taiwan, March 1-5, 2005.

15. Salzmann, C., D. Gillet, and P. Hugeinin, "Introduction to real-time control using LabVIEW with an application to distance learning" in Intl. J. Engg. Education 16(3), 255-272, 1999.

16. Whysong, C.Y., J. Lo, and P. Mallikarjunan, "Improving ethics studies through a spiral themed curriculum in Biological Systems Engineering" in Proceedings of the 2006 ASEE Annual Conference and Exposition, Chicago, IL, June 18-21, 2006.

17. Whysong, C.Y., Lo, J., and P. Mallikarjunan, "Improving ethics studies through a spiral themed curriculum: Implementing ethics discussion at the sophomore level" in Proceedings of the 2007 ASEE Annual Conference and Exposition, Honolulu, HI, June 24-27, 2007. 